\title{
PHARMACO-ECONOMIC ASPECTS OF ANTIBIOTIC PRESCRIPTIONS IN CLINICS OF KATHMANDU
}

\section{ABSTRACT}

\author{
Jauhari A C*, Pokharel A*, Palikhe N**, Shrestha N*, Rao B S*
}

Antibiotics (AB) are the most widely prescribed group of drugs and their use is associated with increasing rate of $\mathrm{AB}$ resistance. Nearly one third of prescriptions of physicians for colds, upper respiratory tract infections and bronchitis are of $\mathrm{AB}$ as documented in previous studies. Antibiotic use is associated with increased cost of financial burden, which may be difficult to be borne by the patients in developing countries like Nepal.

The objective was study the prescribing pattern of Antibiotic preparations in various diseases and to find out how the treatment could become more pharmaco-economic without compromising the quality of service. A cross sectional study of prescription pattern of antibiotics/drugs in which antibiotics were used from randomly selected 20 private clinics of four major specialties in Kathmandu valley.

Total No. of prescriptions audited were 386, average number of drugs/per prescription was 2.74 .

Maximum antibiotics were prescribed for age group 21-40 years in gynecological, surgical and medical problems, in Pediatrics maximum AB were prescribed between 1-12 years.

Minimum antibiotics were prescribed between 13-20 years for gynecological and Pediatric problems. In medical and surgical problems, minimums AB were administered between 41-60 years. Above 60 years almost no AB were used.

Males were prescribed more AB than females (73\% for surgical, $62 \%$ for medical and $53 \%$ for Pediatric problems)

Only in $20.25 \%$ patients, $A B$ were prescribed after proper diagnosis and sensitivity tests

Maximum cost of prescription was 510 Nepali rupees (NR) for treatment of STD in Gynecology.

\section{Key Words: Antibiotics, Cost, Human Immune deficiency Virus, Kathmandu, Private Clinics, Pharmacoeconomic, Sexually Transmitted Diseases.}

\section{INTRODUCTION}

One of the leading causes of death is infectious disease thought the world. Discovery and development of vaccines and antibiotics $\mathrm{AB}$ have minimized this fatality rate to some extent. Now the major obstacle, medical science is facing is of drug resistance microorganisms, which might be due to misdiagnosis and overwhelming prescriptions of large number of drugs.

As more strong $\mathrm{AB}$ were discovered leading to development of more and more resistant strains of microorganisms. Finally we are digging deep into the barrel of antibiotics. ${ }^{1} \mathrm{AB}$ is often most used or misused drugs ${ }^{2-8}$ as reported earlier. In Nepal there are few reports about antibiotic survey. ${ }^{9}, 10$

* Nepal Medical College, Jorpati, Kathmandu, Nepal.

** Kathmandu University, Karve, Nepal.

*** Kathmandu Medical College, Duakote, Bhaktapur, Nepal.

Address for correspondence : $\quad$ Dr. Akhilesh Chandra Jauhari 
It has been seen that approximately 12 million antibiotic prescriptions resulted from respiratory infections accounting for $21 \%$ of all antibiotic prescriptions to adults accounting for 47.2 million (pounds sterling) in expenditure in the United Kingdoms. ${ }^{11}$ Moreover; there is a tendency of prescribing costly and latest antibiotics. Such 'ambitious prescription' has lead to many concerns, not only the development of resistant strains of microbes but also rising health costs. Reports related to overuse of AB in Nepal is yet to be estimated. Earlier a survey of awareness of patients about the use of $\mathrm{AB}$ from some hospitals and clinics of Kathmandu valley was undertaken. ${ }^{12}$ In this study 178 patients were interviewed by a multi graded questionnaire, showing that $54 \%$ patients had no awareness of $\mathrm{AB}, 51.5 \%$ were ignorant about the action of $\mathrm{AB}$ and $89.5 \%$ had no knowledge about the side effects.

This background prompted to undertake this survey on the pattern of ABs prescriptions in 20 private clinics (Five of each of four major specialties, viz medicine, surgery, pediatrics and Gynecology) in Kathmandu valley and to work out pharmacoeconomic of these prescriptions.

\section{SUBJECTS \& METHODS}

1. Inclusion \& exclusion criteria: The patients of outdoor departments of medicine, surgery, pediatrics \& gynecology in 20 private clinics of Kathmandu valley and prescriptions containing $\mathrm{AB}$ alone or with other drugs were included in this study. The patients of other specialities, indoor and follow up cases were precluded from this study.

2. Study area: Random selection by Lottery method was made from 20 private clinics as to diverse specialties.

\section{SIZE OF DATA}

Fifty encounters receiving $\mathrm{AB}$ were made from each selected sample clinic of the chosen prescriber. The total size of the sample was 386 .

\section{TOOLS OF DATA COLLECTION}

Prescription audit was done with the prescriptions of patients who were prescribed $\mathrm{AB}$ by their physicians in their clinics.

\section{FIELD TEST OF DATA}

Field test of the data-collecting tool was done in New Boudha Pharmacy \& Baudha X-ray Diagnostic center, Kathmandu valley

\section{Coding}

The data was coded as below

1. Age distribution: Below 1yr., 1- 10yr, 11-20 yr, 21-30 yr, 31-40y, 41-50y, 51-60yr, >60yr.

2. Sex: Male and female.

3. The total number of drug prescription and the cost of therapy were also noted by using SIMS/MIMS/DRUG INDEX.

\section{ANALYSIS OF DATA}

Data was tabulated and analyzed using tally bars, pie diagrams and MS Excel for windows 2000.

\section{RESULTS}

I. Age distribution: of patients receiving antibiotics is as shown in Table 1

II. Sex distribution shown in Table II.

Males were prescribed more antibiotics (73\% for surgical, $62 \%$ for medical and $53 \%$ for Pediatric problems)

III. Table III Shows Total No. Prescriptions, \% of number of prescriptions/specialty \& Average no. of drugs/

Table I : Age Distribution

\begin{tabular}{|c|c|c|c|c|}
\hline $\begin{array}{c}\text { AGE } \\
\text { GROUP }\end{array}$ & $\begin{array}{c}\text { GYNECOLOGY } \\
(\mathrm{n} 1)\end{array}$ & PAED. (n2) & SURGERY (n3) & MEDICINE (n4) \\
\hline$>1 y$. & - & $\begin{array}{c}8.5 \mathrm{M} \pm 1.60 \\
8(8 \%)\end{array}$ & - & - \\
\hline $1-10 y$ & - & $\begin{array}{c}7.47 \pm 1.91 \\
88(88 \%) \text { (Max.) }\end{array}$ & $\begin{array}{c}8 \pm 1.73 \\
9(10.46 \%) \\
\end{array}$ & - \\
\hline $11-20 y$ & $\begin{array}{c}15 \pm 3.03 \\
6(6 \%) \\
\end{array}$ & $\begin{array}{c}13.5 \pm 2.38 \\
4(4 \%)(\mathrm{Min})\end{array}$ & $\begin{array}{l}16.26 \pm 2.71 \\
15(17.44 \%) \\
\end{array}$ & $\begin{array}{c}16.66 \pm 2.90 \\
12(12 \%) \\
\end{array}$ \\
\hline $21-30 y$ & $\begin{array}{c}26.40 \pm 2.46 \\
66(66 \%)(\mathrm{Max})\end{array}$ & - & $\begin{array}{c}26.21 \pm 2.36 \\
57(66.27 \%)(\mathrm{Max})\end{array}$ & $\begin{array}{c}26.23 \pm 2.47 \\
52(52 \%) \\
\end{array}$ \\
\hline $\begin{array}{l}31-40 y \\
41-50 y\end{array}$ & $\begin{array}{c}47.03 \pm 2.51 \\
28(28 \%)\end{array}$ & - & $\begin{array}{c}43 \pm 1.58 \\
5(5.81 \%) \text { (Min.) }\end{array}$ & $\begin{array}{c}47.14 \pm 2.38 \\
28(28 \%)\end{array}$ \\
\hline $\begin{array}{c}51-60 y \\
>60 y\end{array}$ & & - & & $\begin{array}{c}63.75 \pm 2.12 \\
8(8 \%) \\
\end{array}$ \\
\hline
\end{tabular}

Number of encounter $=386(n 1=100, n 2=100, n 3=86, n 4=100)$ 
Table II : Sex Distribution

\begin{tabular}{l|cc}
\hline \multicolumn{1}{c|}{ SPECIALITY } & Male & Female \\
\hline GYNECOLOGY & - & 100 \\
\hline MEDICINE & 62 & 38 \\
\hline SURGERY & 63 & 26 \\
\hline PAED. & 47 & 53 \\
\hline
\end{tabular}

Table III : Total No. Prescriptions, \% of prescriptions/specialty \& Average No. of durgs/prescription (for checking polypharmacy)

\begin{tabular}{c|c|c|c|cc}
\hline TOTAL No. OF PRESCRIPTIONS (386) & $\begin{array}{c}\text { GYNE. } \\
\boldsymbol{\%}\end{array}$ & $\begin{array}{c}\text { MED } \\
\boldsymbol{\%}\end{array}$ & $\begin{array}{c}\text { SUR. } \\
\boldsymbol{\%}\end{array}$ & $\begin{array}{c}\text { PED } \\
\boldsymbol{\%}\end{array}$ \\
\hline . & 31 & 25 & 16 & 28 \\
\hline AVERAGE No. OF DRUGS/PRESCRIPTION & 3.2 & 2.58 & 2.3 & 2.8 \\
\hline
\end{tabular}

Table IV

\begin{tabular}{c}
\hline HEALTH PROBLEMS \\
WHERE AB WAS USED, BUT NOT REQUIRED \\
\hline Pain lower abdomen \\
\hline Dysmenorrhoea \\
\hline Aminorrhoea \\
\hline Epigastric pain \\
\hline Pain in chest \\
\hline Abdominal pain \\
\hline Headache, vomiting
\end{tabular}

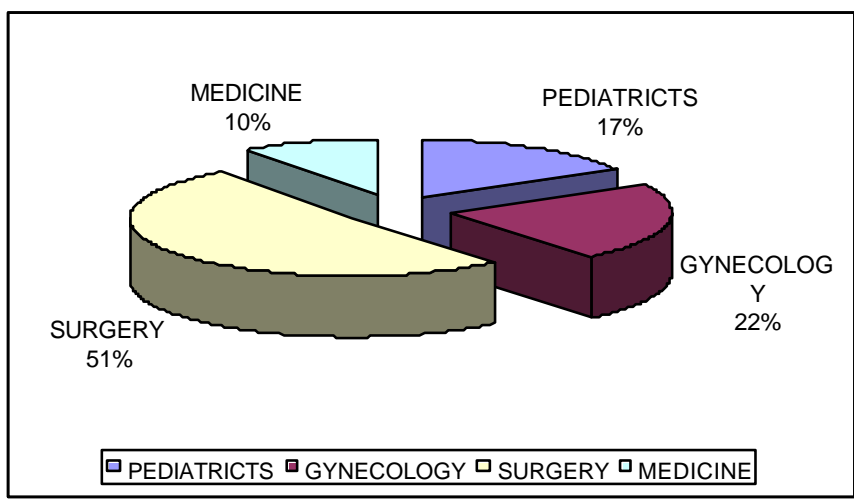

Fig. 1 : Use of AB. After proper investigations

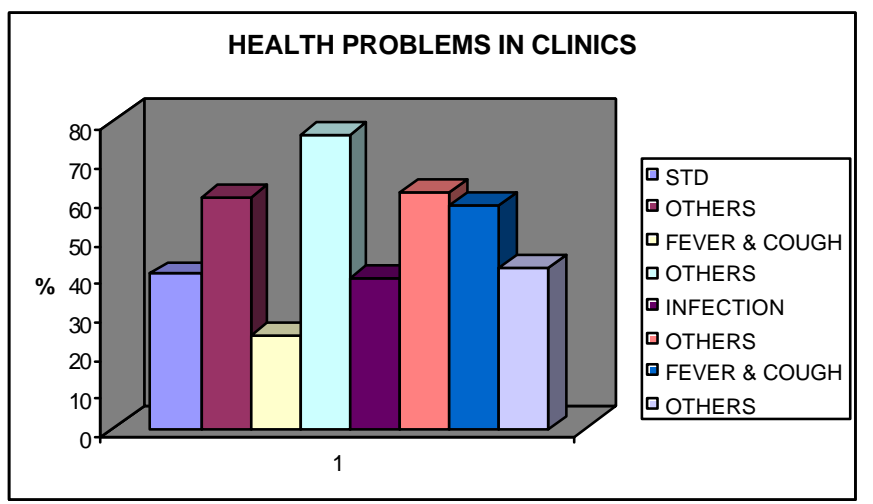

Fig. 2 : Showing maximum health problems in clinics

prescription (for checking polypharmacy)

IV. Diagnosis:

The study showed that in clinic $20.25 \%$ of patients was prescribed $\mathrm{ABs}$ after proper diagnosis and the rest

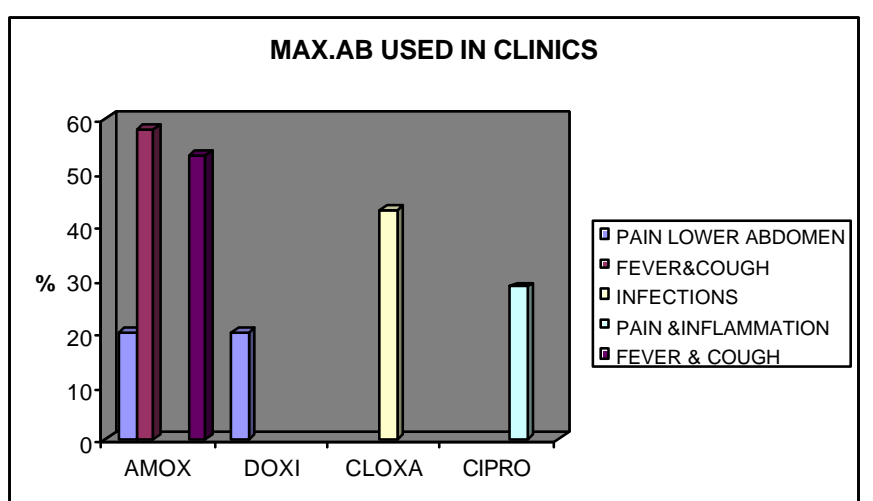

Fig. 3 : Showing commonest health problems \& commonest AB used in different specialities in Hospitals

without it.

Out of $20.25 \%$ cases that were prescribed $A B$ after investigations Figure I shows the breakup of $20.25 \%$ ABs prescriptions in different specialties in clinics.

V. Bar diagram I show health problems in different specialties:

VI. Use of different $\mathrm{AB}$ for different health problems:

Table IV shows health conditions, where the AB use was unnecessary and extra expenditure on $\mathrm{AB}$ has increased the cost of prescriptions

Bar diagram II. Shows commonest health problems and commonest $\mathrm{AB}$ used in different specialities in clinics

The use of different $\mathrm{AB}$ for different health problems has been shown in bar diagram III, IV. 


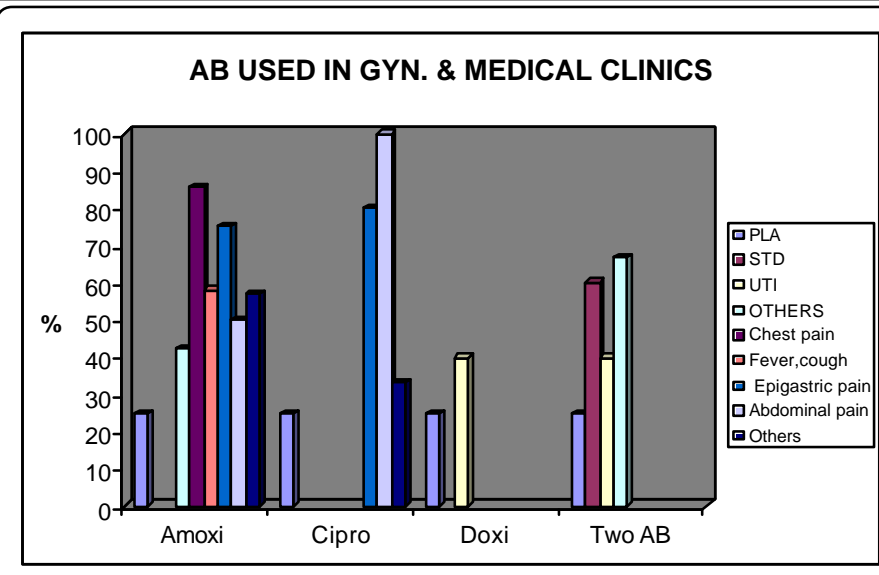

Fig. 4 : Bar Diagram

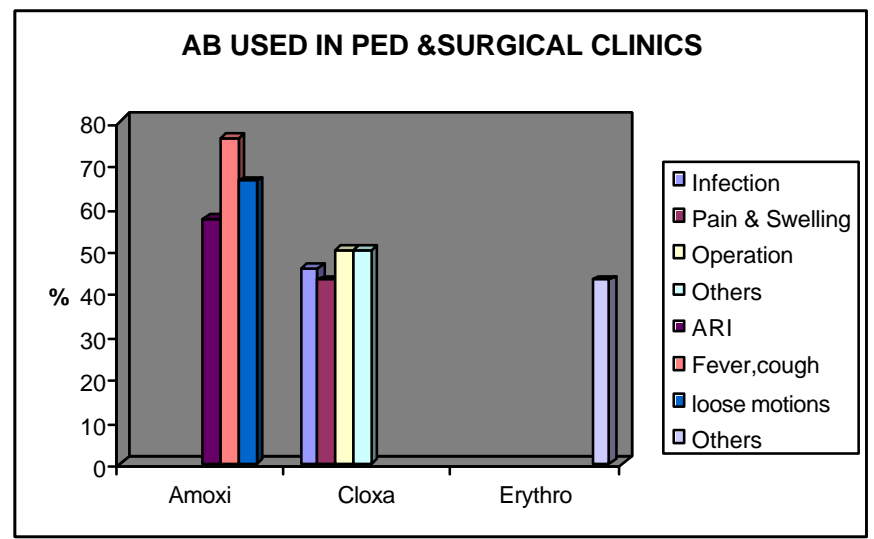

Fig. 5 : Use of Ab in Surgical \& Pediatrics Clinics

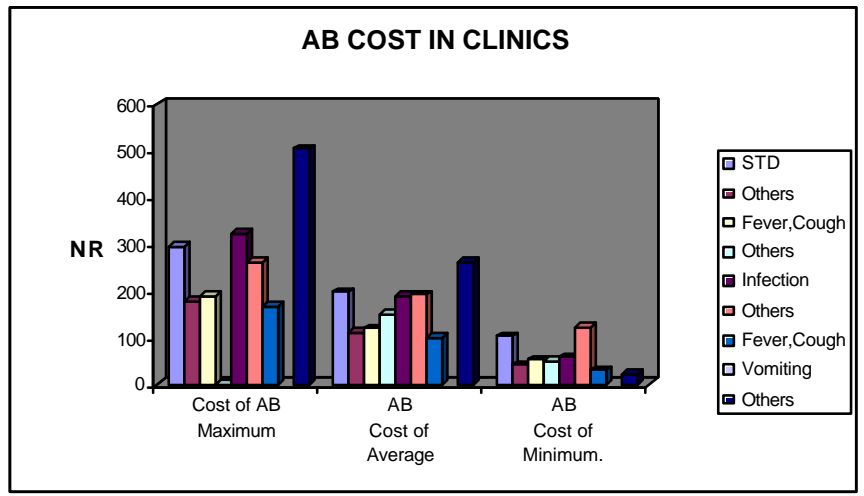

Fig. 6a : Showing pharmaco-economics of ABs treatment in all health problems in clinics (cost in NRs.)

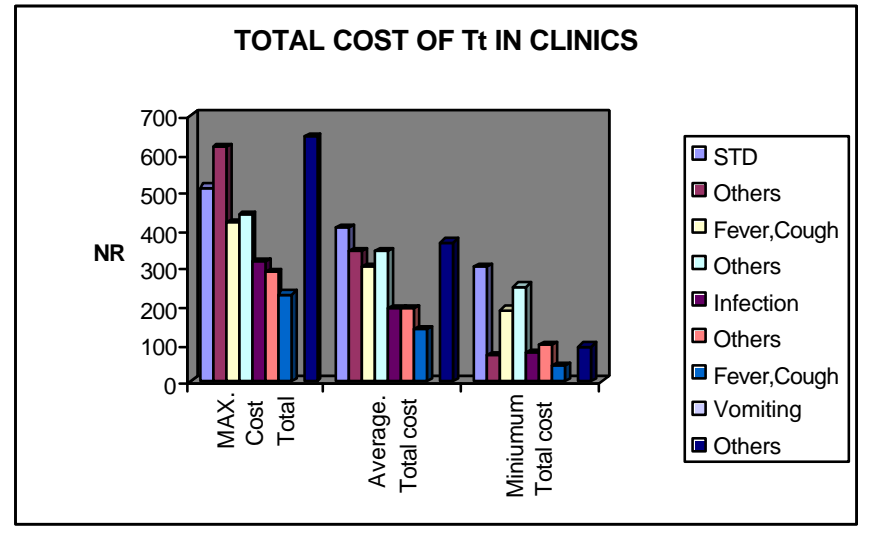

Fig. 6b : Showing pharmaco-economics of ABs treatment in all health problems in clinics (cost in NRs.)

\section{DISCUSSION}

As shown in Table IV of this study even taking the average costs of AB 177.5, 116, 112, and 151. 99.75, 84. NR spent by patients was not required.

In gynecological clinics total number of prescriptions were 160 , which was maximum, but minimum prescriptions were in surgical clinics that were 84. Maximum average number of drugs per prescription was 3.14 in gynecological clinics and minimum average number was 2.34 drugs /prescription in surgical clinics.

Out of prescribed drugs prescriptions of Abs were $20.25 \%$ out of which $61.84 \% \mathrm{AB}$ was prescribed without any proper investigations. In those cases were investigations were done only in $8.6 \%$ patients culture /sensitivity was done before $\mathrm{AB}$ therapy; in $29.56 \%$ patients some investigations were done before $\mathrm{AB}$ used.

\section{PHARMACO-ECONOMIC ASPECTS OF AB THERAPY}

Pharmaco-economic aspects of $\mathrm{AB}$ treatments in different specialties are shown in Table VII.

Quinolones and fluoroquinolones were the Abs of choice in private clinics.

This is an alarming situation to improve this alarming situation

\section{RECOMMENDATIONS}

Following may be suggested---

Effective information and dissemination strategies for public at all levels should be implemented.

A massive consumer awareness programme on the use of $\mathrm{ABs}$ should be conducted to produce awareness amongst the common people.

A massive education programme at school level could be ideal. Medical professionals and pharmacists should be invited by school authorities to educate the younger generation not only against antibiotics but also against other health hazards on the lines of AIDS DAY ( $1^{\text {st }}$ of December).

A national antibiotic policy should be formulated and standard treatment guidelines for Physicians should be issued.

Culture \& sensitivity reports of commonly used $\mathrm{AB}$ should be available from time to time

Importance of investigations should be stressed in chronic cases Prescriber should be more careful in using expensive and multiple ABs. Generally oral drugs are cheaper than injections, the $1^{\text {st }}$ generation drugs are usually cheaper then the latest generations. ${ }^{13}$ In situations where two or more then two ABs 
are equally effective, cheaper alternative should be the choice, without compromising the patient care. This practice is more pharmaco-economic. There are many common infections that can be treated efficiently with older and cheaper ABs. ${ }^{14}$ It may be valuable to categorize $\mathrm{ABs}$ into different groups and hold some $\mathrm{ABs}$ in the reserve group for more restricted use. ${ }^{15}$

A WHO expert committee (1989) has proposed that ABs like quinolones, third \& fourth generation Cephalosporins and vancomycin may be kept as 'reserve' ABs for resistant hospital strains infections. ${ }^{16}$

Peer group discussions, availability of sensitivity pattern of local bacterial pathogens can be very helpful in selecting AB. ${ }^{16,17}$

\section{ACKNOWLEDGMENT}

Authors are grateful to Prof. S.K. Bapat, HOD, Pharmacology KMC \& Prof. V, K. Kulshrestha HOD Clinical Pharmacology, Mr. Arun Kumar, Asst. Prof. Clinical Bio-Chemistry, and Nepal Medical College for their generous help. We are thankful to Dr. Navin Thapa, Kathmandu University Medical School and lastly but not the least to Mr. Saffar Mansoor for their guidance.

\section{REFERENCES}

1 Hervey K Initi ati ves to i nprove anti bi otic use Ed torial, Austral i an Prescri ber 1999; 22; 226.

2 Corzal es R Steiner J.F., Sande MA Ati bi di c prescribing for adul ts with col ds, upper respi ratory tract i infecti ons and bronchi ti is by anbul at ory care physi ci ans. J AMA 1997; 278: 901-904.

3 Pellizzer A M, Cal langhan CJ. O, Branl ey P, Thonsosn B \& KrumH Pd yphernacy in a maj or Austral i an Teaching Hospital . Aus. J. hosp. Pharnacy 1998; 28: 432- 435.

4 MeManus P, Fannond ML., Whi cker S. D, Pri mnose J.G ,
Nant A \& Fai ral I S.R Anti bi otic use in Austral i an conmani ty1990-1995. MA 1997; 167: 124- 126.

5 Couper MR Strategies for rati onal use of anti nncrobial s Q.IIf.Ds. 1997; Supd 1: S154156.

6 Pricst P., Yudki n P., NeNu ty C \& Mant D Anti bacterial prescri bi ng and anti bacteri al resi stance in End $\mathrm{i}$ sh general practi ce: cross secti onal study. BMI 2001; 328: 1037-1041

7. Veng-Beringer A, Enperical anti mucrobial prescri bing i npact on outcone and cost, Hbs. Pharm 1998, vol 33, no. 10, 1208 1213.

8 Jahari AC \&ohorey AC Attibi dic ics in aate corconery heart di seases. MV 2001; 2: 103-104.

9 Kafl e KK, Pradren Y.MS, Strestha S.B, Prasad RR, Strestha $N \&$ Das P. L Prescri bi ng and di spensi ng practi ces in PHC fad lities of Tera districts of Nepd. J. I rt. N\$d 1996, 18 ๔-66

10. J osh M., Srivastava K Meda K Study of anti bacterial usage at T. U teaching hospi tal Today's drugs-3. J. Ins. NAd 1991; 13: 207-213.

11. Rol and F. Grossman, Di sease Managenent of Pul nonary I nf ecti on, CHEST 1998, 113: 2055-210S.

12. Pokhere A Pal ikhe N, Strestha N \&J ahari AC A survey of pati ent's avareness about anti bi oti cs use in Katmandu Mg 2004 (In Press).

13. Ryan $M$, Yu e B Bond $C$, Tay or B Scati sh general practi aner's atti tudes and knowedge in respect of prescri bi ing costs. B. Ned. J. 1990; 300: 1315- 1318.

14. Sinth A G ve a second thought before using atti bi oti cs leal th Acti on 1990; 3: 103- 104.

15. Kuni n OM Rati onal use of anti bi otics. MADDug i ff ornation 1990; 4: 47.

16. Anonynous Reserve anti bi oti cs WHO Drug i nf or mat i on 1989; 3: 165- 166.

17. Lowbury BL, Ayliffe GA, Ceddes AM M M I i ans JDEob. Control of hospital infection a practical hand book London: Chapnan and Hall 1981

$$
25 \cos
$$

